\title{
ISO 21090
}

National Cancer Institute

\section{Source}

National Cancer Institute. ISO 21090. NCI Thesaurus. Code C81895.

An international standard that provides a set of data type definitions for representing and exchanging basic concepts that are commonly encountered in healthcare environments in support of information exchange in the healthcare environment and establishes the semantics and representations for their use. 